\title{
Recursos simbólicos e imaginação no contexto da contação de histórias
}

\author{
Silvana Goulart Peres ${ }^{1}$, https://orcid.org/0000-0002-9465-5440 \\ Renata Magalhães Naves', https://orcid.org/0000-0002-7423-1309 \\ Fabrícia Teixeira Borges ${ }^{1}$, https://orcid.orq/0000-0002-9341-2738
}

\begin{abstract}
Resumo
O presente artigo tem como proposta analisar a contação de histórias e a interação entre professora e crianças com ênfase na utilização dos recursos simbólicos - e, por conseguinte, a expansão da imaginação por meio do aporte teórico da Psicologia Histórico-Cultural. A pesquisa, de cunho qualitativo, utilizou, para a construção dos dados, observações e videogravação de episódios de contação de histórias em uma biblioteca escolar da Educação Infantil. Posteriormente, foram realizadas microanálises de episódios interativos. Os participantes da pesquisa foram 18 crianças entre 4 e 5 anos e 1 professora de biblioteca escolar da Educação Infantil. A contação de histórias, feita de forma interativa, potencializou o uso de recursos simbólicos quando os participantes fizeram referências às suas experiências cotidianas permeadas por afetividade - o que, consequentemente, desencadeou a expansão dos processos imaginativos.
\end{abstract}

Palavras-chave: Histórias; imaginação; crianças.

\section{Symbolic resources and imagination in the context of storytelling}

\begin{abstract}
This article aims to analyze storytelling and the interaction between teacher and children with emphasis on the use of symbolic resources and, therefore, the expansion of the imagination through the theoretical contribution of Historical-Cultural Psychology. The qualitative research used, for the construction of the data, observations, and videotaping of episodes of storytelling in a school library of Early Childhood Education. Subsequently, microanalysis of interactive episodes has performed. The participants of the research were 18 children between 4 and 5 years old and 1 teacher of school library of Early Childhood Education. Storytelling, interactively, enhanced the use of symbolic resources when participants made references to their everyday experiences permeated by affectivity - which, consequently, triggered the expansion of imaginative processes. Keywords: History; Imagination; children.
\end{abstract}

\section{Recursos simbólicos e imaginación en el contexto de la narración de historias}

\section{Resumen}

En el presente artículo se tiene como propuesta analizar la narración de historias y la interacción entre profesora y niños con énfasis en la utilización de los recursos simbólicos - y, por lo tanto, la expansión de la imaginación por intermedio del aporte teórico de la Psicología Histórico-Cultural. La investigación, de cuño cualitativo, utilizó, para la construcción de los datos, observaciones y vídeo grabación de episodios de narración de historias en una biblioteca escolar de la Educación Infantil. Posteriormente, se realizaron microanálisis de episodios interactivos. Los participantes de la investigación fueron 18 niños entre 4 y 5 años y 1 profesora de biblioteca escolar de la Educación Infantil. La narración de historias, realizada de forma interactiva, potencializó el uso de recursos simbólicos cuando los participantes hicieron referencias a sus experiencias cotidianas permeadas por afectividad - lo que, consecuentemente, desencadenó la expansión de los procesos imaginativos.

Palabras clave: Historias; imaginación; niños.

1 Universidade de Brasília - Brasília - Brasília, DF, Brasil. 


\section{Introdução}

O contador de histórias tem circulado em vários contextos, como escolas e, mais especificamente, bibliotecas escolares. A contação de histórias é instrumento que serve como ponte para transitar nas dimensões afetivas, cognitivas e sociais do ser humano e ampliar os significados que tornam as pessoas mais humanas, íntegras, solidárias e cidadãs. $\mathrm{O}$ ato de contar histórias pode ser considerado como social e coletivo, que se materializa por meio da escuta afetiva e efetiva (Bussatto, 2013).

O contexto da biblioteca escolar pode favorecer o uso de recursos simbólicos por meio da contação de histórias, pois esses participam do desenvolvimento psíquico da pessoa e são vistos como modalidades internalizadas que guiam a exploração imaginária. O acesso aos recursos simbólicos ocorre por meio de elementos culturais mediadores, como livros, filmes ou canções usados no cotidiano, com alguma intenção.

Quando um elemento cultural é utilizado, seu uso vai além do significado pretendido, pois, carregado de emoção, torna-se significativo para a tomada de sentido. Assim, os recursos simbólicos, de certa maneira, propiciam formas complexas de mediação semiótica com propósito de contribuir para a apreensão de novos eventos e pensamentos (Zittoun, 2007, 2016).

O uso dos recursos simbólicos se situa em dinâmicas semióticas a partir de uma fluidez de tempo (Valsiner, 2012) em que, para um determinado grupo de pessoas, as experiências culturais exigem algum entrelaçamento entre passado e futuro no presente. O ser humano recorre às memórias, aos sentimentos e às emoções para compreender as experiências culturais.

Os significados contidos nas interações verbais contribuem para que as crianças se apropriem das experiências culturais que são engendradas socialmente e sejam capazes de atuar de maneira autônoma em seu cotidiano. Neste trabalho é imprescindível pensarmos que a criança necessita interagir com diversas experiências com o outro e relacioná-las ao seu cotidiano para que haja a expansão da imaginação.

A criança na Educação Infantil desenvolve a imaginação partindo da memória e das funções psíquicas que proporcionam sentido e significado, uma vez que os sentidos pessoais são construídos a partir dos significados disponibilizados socialmente (Daniels, 2008).

Este artigo objetiva analisar a contação de histórias e a interação entre professora e crianças com ênfase na utilização dos recursos simbólicos - e, consequentemente, a expansão da imaginação - com a finalidade de aproximar a tomada de sentido e contribuir para o desenvolvimento dos envolvidos no contexto de contação de histórias em uma biblioteca escolar de Educação Infantil.

\section{Recursos simbólicos para expansão da imaginação}

É recente a noção de recursos simbólicos como objeto de investigação teórica sistemática (Zittoun, 2007). Este conceito, descrito por Zittoun, propõe a compreensão sobre o que cada pessoa faz quando utiliza artefatos culturais ou ferramentas semióticas para enfrentamento de situações novas e imprevisíveis. Os recursos simbólicos são feixes de significados e experiências que envolvem a mediação semiótica - pessoal, com os outros e com o mundo - e exigem uma interação entre as pessoas e os elementos culturais. Tal interação é denominada por nós como experiência cultural. A noção de recursos simbólicos objetiva apreender a dinamicidade e a intencionalidade com que os dispositivos semióticos são utilizados (Bruner, 2002; Zittoun, 2007). Normalmente, as pessoas não se dão conta que fazem uso de recursos simbólicos nas experiências cotidianas (Zittoun, 2007, 2016).

Zittoun $(2007,2016)$ argumenta que algumas atividades, como ler livros ou assistir a filmes, movimentam elementos culturais que proporcionam a utilização dos recursos simbólicos, pois esses elementos exigem experiência imaginária. As histórias contadas na biblioteca podem potencializar o uso da linguagem pelas crianças e a expansão da imaginação. Assim, é possível mencionar alguns episódios em que as histórias contadas para as crianças foram articuladas com suas experiências de vida.

Ainda nessa perspectiva, Zittoun (2007) ressalta a importância da literatura e do cinema como potencial para explorar de forma ampla o acesso e o uso de elementos culturais como recursos simbólicos. Os espaços escolares, a biblioteca, a frequência do uso do livro como elemento cultural podem ser favoráveis para o compartilhamento das experiências simbólicas, incentivando as crianças no processo de imaginação e criação.

Ao contar uma história abordando temas que remetem a valores, amizade, preconceito, etc., articulam-se recursos simbólicos para possibilitar a produção de significados ou ação sobre si, sobre os outros e/ou sobre a realidade compartilhada (Zittoun, 2007). Aprender a usar os recursos simbólicos possibilita a incorporação de novas esferas de experiências sociais conectadas à experiência emocional atrelada ao processo de imaginação.

\section{Processo de imaginação na infância}

A infância e a criança vêm sendo palco de inúmeros estudos e discussões no cenário da Educação e da Psicologia (Mozzer \& Borges, 2008; Moreno, 2009). Nesta interface entre a Educação e a Psicologia, é necessária a discussão acerca do processo de imaginação na infância como fundamental para o desenvolvimento infantil. Pino (2006) afirma que toda produção humana, material e simbólica é constituída a partir das produções imaginárias, ou seja, a natureza criativa é sempre precedida pela atividade imaginativa, possibilitando dizer que a condição humana é constituída a partir do processo imaginário. A imaginação é base da atividade criadora e manifesta-se nos campos da vida cultural, tornando possível a criação artística e científica (Vigotsky, 2004/2009).

O processo de imaginação das crianças vem sendo investigado por pesquisadores de diferentes orientações 
teóricas em Psicologia, como, por exemplo, a HistóricoCultural e a Cultural do Desenvolvimento (Zittoun, 2007, 2016; Vigotsky, 2004/2009, Cruz, 2011; Silva, 2012). Essas correntes teóricas consideram a importância da interação humana a partir da mediação simbólica. A criança é imersa na cultura semiótica permeada por signos desde a tenra idade e, para que haja aprendizado e desenvolvimento, é necessária a mediação a partir dos signos e do Outro (Pino, 2005; Vigotsky, 1984/2007).

A criança, por meio da experiência cotidiana, desenvolve sua imaginação com a mediação entrelaçada pela linguagem. Luria (2006) afirma que

é com base na linguagem que se formam complexos processos de regulação das próprias ações do homem, embora, no início, a linguagem seja uma forma de comunicação entre o adulto e a criança e a linguagem vai assim gradualmente se transformando em uma forma de organização da atividade psicológica humana (p. 197).

O desenvolvimento deve ser visto como processo histórico no qual o ambiente social da criança leva ao desdobramento dos processos de mediação em várias funções mentais superiores (Vigotsky, 1984/2007; Luria, 2006). Os autores afirmam que as crianças assimilam a linguagem um produto do desenvolvimento sócio-histórico - e usam-na para analisar, generalizar e codificar experiências. A imaginação pode ocorrer dentro de um sistema de pensamento lógico-verbal ou estar firmemente ligada à experiência prática.

Vigotsky (2001/2010) argumenta que as crianças não imaginam mais do que os adultos, pois Ihes falta experiência de vida. Para o autor, "tudo o que conhecemos do que não houve na nossa experiência nós o conhecemos através da imaginação" (p. 203). Nos estudos sobre a imaginação e a atividade criadora, há dois tipos de atividades: a reprodutiva, ou da memória, e a combinatória, ou criadora (Vigotsky, 2004/2009). Para ele, a atividade reprodutiva tem base na repetição, na memória e nas lembranças. Essa atividade se pauta na constituição da plasticidade, que permite que ela seja modificada e conserva as marcas dessa modificação.

A criança necessita da atividade reprodutiva para elaborar a atividade criadora, pois, quando ela brinca, não apenas recorda as experiências vivenciadas, mas as reelabora de forma criativa. A atividade criadora do ser humano tem como resultado a criação de novas imagens ou ações, e não a reprodução de impressões ou ações anteriores à sua experiência. É chamada de atividade criadora do humano aquela em que se cria algo novo (Vigotsky, 1984/2007; 2004/2009).

Para que se tenha uma nova criação, é necessária a interação com o outro mediada por objetos semióticos, e é por meio do intercâmbio da linguagem que aprendemos a utilizar elementos culturais e os recursos simbólicos (Zittoun, 2016). Desta forma, pensar no contexto da contação de histórias tendo como mediadora a professora e na contribuição que esse ambiente traz para o desenvolvimento dos recursos simbólicos como forma de apreensão para suscitar a expansão da imaginação é imprescindível.

\section{Método}

\section{Delineamento}

Nosso estudo foi delineado a partir de um recorte de pesquisa maior sobre o processo de significação da professora e as interações ocorridas no contexto da biblioteca escolar. Trata-se de pesquisa de cunho qualitativo por aproximar-se das intenções de pesquisa e ser modelo que permite compreender gradualmente o fenômeno social, além de possibilitar a entrada do pesquisador no contexto dos participantes, afinal, os fenômenos sociais são vistos de maneira holística (Bauer \& Gaskell, 2002; Creswell, 2014).

Os instrumentos para a construção de dados foram a observação direta com registro no diário de bordo em relação ao espaço físico e à dinâmica entre a professora da biblioteca escolar e as crianças do segundo período de Educação Infantil, bem como videogravação de episódios de contação de histórias.

O registro em vídeo permitiu conservar detalhes que a escrita poderia ter deixado de registrar. $\mathrm{O}$ vídeo funcionou como memória audiovisual, captando comportamentos e mostrando-nos fatos que só percebemos quando assistimos repetidas vezes (Carvalho, 1996).

\section{Campo de pesquisa - Biblioteca Escolar: que espaço é esse?}

O estudo foi desenvolvido em uma escola pública de Educação Infantil do Distrito Federal que possui Biblioteca ativa. O espaço da biblioteca é amplo e possui estantes com variados livros de literatura infantil, em que a decoração é repleta de desenhos que ilustram algumas cenas das histórias infantis.

\section{Participantes}

Participaram da pesquisa Sherazade (nome fictício) uma professora contadora de histórias da Biblioteca de uma instituição de Educação Infantil da Secretaria de Estado de Educação do Distrito Federal e alunos de uma turma de segundo período da Educação Infantil. Havia 18 (dezoito) alunos presentes, sendo 10 (dez) meninos e 8 (oito) meninas, com idade entre quatro e cinco anos.

\section{Procedimentos para construção de dados}

Foram realizadas quatro videogravações com a utilização de Filmadora Mini-DVD modelo VDRD 300 Panasonic e um tripé, totalizando, aproximadamente, 3 horas e 5 minutos de conteúdo, que continha os momentos da contação de histórias em dias distintos. Foi selecionado aquele que continha dados mais relevantes aos objetivos deste estudo. 
As histórias contadas foram organizadas pela professora da biblioteca, sem interferência das pesquisadoras.

A videogravação contemplada teve duração de 38 minutos e 90 segundos e mostrou-se um recurso de pesquisa produtivo por permitir o resgate posterior da organização do tempo, do espaço, das cenas, das falas e das interações entre a professora e as crianças, entre crianças e crianças e crianças e o espaço exterior no contexto da contação de histórias na biblioteca.

As interações no vídeo foram degravadas e seu contexto foi transcrito na íntegra por meio de microanálise, observando a ocorrência das interações e a importância da contação de histórias. Na transcrição dos episódios, houve apreensão e descrição das interações verbais e não verbais tais como ocorridas nas imagens em movimento, e foram descritas as ações e interações simultâneas que aconteceram ao decorrer da videogravação.

As transcrições permitem ao pesquisador uma análise criteriosa a respeito de cada fala, ações e expressões dos participantes da pesquisa. Assim sendo, enquanto fazíamos a transcrição, percebemos o quanto as palavras, ações e gestos carregam significados diversos, a depender do contexto de análise.

A retomada da leitura nos proporcionava novas interpretações a respeito do processo interativo que estava em estudo. Destacamos que assistir ao vídeo, fazer as transcrições, lê-las e assistir novamente ao vídeo são estratégias valiosas que devem estar entrelaçadas, visando a qualidade das análises e discussões dos dados.

Por interações consideramos os diálogos que foram transcritos de forma literal para a construção de temas por meio de análise dialógica da conversação adaptada à Psicologia (Pontecorvo, Ajello, \& Zuccermaglio, 2005; Caixeta, 2006). Após a análise dos temas, fez-se a seleção de algumas passagens da conversação e procedeu-se à análise para identificar os processos interativos nos turnos das falas dos participantes da pesquisa.

\section{Resultados e discussões}

Os participantes da pesquisa se mostraram bem ambientados ao contexto da biblioteca e se manifestaram de forma espontânea em suas interlocuções nos apresentando os sentidos e significados constituídos em seus processos de desenvolvimento a partir das experiências cotidianas. Os resultados encontrados durante a contação de histórias pela professora em interação com as crianças foram organizados em mapa de significados das microanálises em seis episódios, estruturados em eventos, conforme Figura 1.

Com base no mapa de significados, apresentaremos alguns dos episódios de interação da professora com os alunos por meio da contação de histórias no contexto da biblioteca escolar da Educação Infantil.

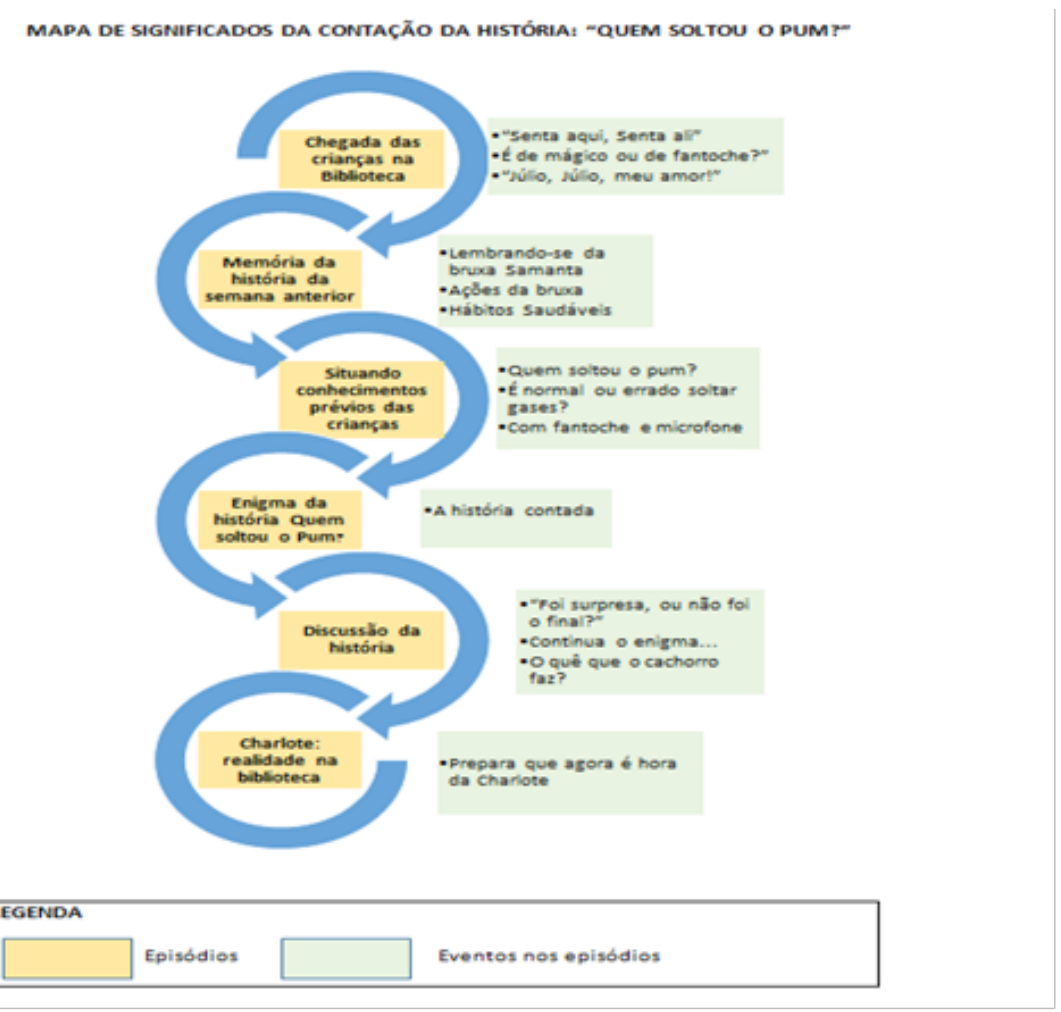

Figura 1. Mapa de significados da contação da história: Quem soltou o pum? 


\section{Microanálise do episódio "Chegada das crianças à Biblioteca"}

O episódio trata da chegada das crianças à Biblioteca. Evidenciamos diálogo entre as crianças no momento em que a professora organiza a turma. As crianças não tiveram oportunidade de escolher seus lugares. A estratégia de acomodação não foi impedimento para que elas pudessem interagir umas com as outras, como se vê no evento 2 .

(1) Paulo: É de mágico, não é!?

(2) José: É fantoche!

(3) Paulo: Ele falou que é de mágico.

(4) Joana: Gente, dá para ver que não tem muito espaço pra ficar ali de trais.

(5) Artur: Eu tenho um fantoche do Kiko e do Chaves e também da Chiquinha. (Evento 2) - "É de mágico ou de fantoche?"

No evento 2 é possível notar interação criança-criança e criança-ambiente por meio do diálogo entre quatro delas, motivado pelo cenário, a partir de uma curiosidade: se a contação envolveria mágico ou fantoche, como vemos no diálogo, nas enunciações (1) e (2). Assim, a composição do cenário também é um aspecto de mediação simbólica relevante que dispara o processo imaginativo (Vigotsky, 2004/2009) e a interação verbal entre as crianças. Notamos que a interação se ancora na dinamicidade da atividade na qual essas crianças estão imersas. Enquanto aguardam a contação de histórias, elas interagem, dialogando sobre as estratégias que serão utilizadas para contação de histórias. Podemos destacar nesse evento o quanto as significações tomam conta das discussões das crianças partindo de suas experiências. O significado compartilhado é negociado nas interações e permite que as pessoas entendam umas às outras (Bruner, 2002; Zittoun, 2016).

As tensões geradas na discussão convidam as crianças a uma tomada de sentido, como mostrado na enunciação (4), e a criação de resposta na qual as crianças trazem artefatos culturais presentes no cotidiano - no caso desse evento, por imaginarem que a contação de história será feita por fantoche. Nesse instante, uma criança lembra-se de seus fantoches e verbaliza essa lembrança, como apresentado no enunciado (5). Assim, os mecanismos da imaginação nos auxiliam na compreensão sobre a importância do papel social e cultural na atividade de criação, pois o que é visto e ouvido pela criança proporciona pontos que apoiam futuras criações.

\section{Microanálise do episódio "Situando conhecimentos prévios das crianças"}

No episódio a seguir, a professora inicia um diálogo com as crianças a partir do título da história a ser conta- da. As crianças correspondem às questões enunciadas por Sherazade, dialogando sobre o tema apresentado.

6) Sherazade: E hoje nós vamos contar outra história. A tia Sherazade nunca contou essa história aqui. Sabe qual é a história?

(7) Carlos: Não.

(8) Sherazade: Quem soltou o Pum?

(9) Tatiana: Não sei.

(10) Sherazade: Ninguém sabe Quem soltou o Pum?

(11) Crianças: Não.

(12) Sherazade: Nem eu sei. Acho que vocês vão ver agora quem foi que soltou. Se prestar bastante atenção na história.

(13) Sherazade: Agora, o quê que é pum?

(14) Joana: Pum é um peido.

(15) Jorge: Chama gás.

(16) Sherazade: Como é que é?

(17) Jorge: É gás.

(18) Sherazade: Gás, mas gás de cozinha?

(19) Crianças: Não.

(20) Caio: É gás de soltar.

(21) Sherazade: Mas quem que solta esses gases?

(22) Crianças: Pessoas, a gente.

(23) Sherazade: A gente solta esses gases?

(24) Caio: Sim! (Evento 1 - Quem soltou o Pum?)

No evento 1 - Quem soltou o Pum? - da microanálise "Situando conhecimentos prévios das crianças", a professora, ao decorrer da contação de histórias em interação com as crianças, continua em pé, em movimento, com expressões gestuais andando de um lado para o outro e sempre com o olhar direcionado às crianças. A partir deste contexto, compreendemos que os movimentos também promovem significados, pois toda expressão gestual "pode tornar-se material para a expressão da atividade psíquica, posto que tudo pode adquirir uma valor semiótico, tudo pode tornar-se expressivo" (Bakhtin, 2014/1929, p. 53).

Nesse movimento interativo, a professora instiga a imaginação das crianças por meio de questionamentos em 
relação ao título da história que será contada, conforme a enunciação (8). As crianças, no primeiro instante, atentas aos questionamentos, mostram estranhamento e vergonha, transparecidos em suas expressões faciais. Mas, a partir da indagação da professora sobre o que é "pum", vista na enunciação (10), as crianças, de forma confortável, narram sobre os seus conhecimentos prévios, os quais se destinam a transportar significados que exigem uma experiência imaginária (Vigotsky, 2004/2009; Zittoun, 2016) e podem desempenhar um papel relevante na aprendizagem, no momento em que as crianças tentam relacionar a palavra com suas experiências pessoais.

É importante notar que, ao decorrer da interação, lidar com a palavra "pum" e seu significado não foi embaraçoso para as crianças. Mesmo com a inferência da professora, ao questionar sobre o gás de cozinha, apresentada na enunciação (18), elas expressaram em suas falas os conceitos cotidianos que internalizaram referentes ao tema em discussão. A palavra assumiu uma relação de intersubjetividade no diálogo, pois, conforme Bruner (2002), somos seres que negociam os significados, seja por meio das palavras, dos gestos ou das ações.

\section{Microanálise "Enigma da história 'Quem soltou o Pum?'”}

No episódio apresentado, Sherazade faz a contação de história utilizando fantoches. As crianças estão acomodadas em frente ao cenário, onde algumas se sentam no chão e outras, em cadeirinhas.

(25) Sherazade: Então eu vou contar a história. Meu melhor amigo é meu pum nada me deixa mais feliz que soltar o pum. Muitas vezes, as pessoas olham feio pra mim porque o pum faz barulho e atrapalha a conversa dos adultos. Meus pais dizem que isso só acontece porque tem hora certa pra soltar o Pum. Quando eu solto na hora errada, na frente dos outros, eu acabo levando maior bronca à toa. Aiaiaiaiahhhh (lamentos).

Teve uma vez, que eu, assim por distração, soltei um pum no jardim do prédio onde a gente morava e levei a maior bronca da síndica: 'Joãozinho, quantas vezes vou ter que repetir? Não quero Pum aqui! Eu vou falar com a sua mãe!' E aí ela falou pra minha mãe e a minha mãe ficou brava de verdade.

Ainda bem, que depois, a gente se mudou pra uma casa grande, com jardim florido maior ainda. Aí era uma feeeesta!!! Eu soltava o Pum no quintal e ele não incomodava ninguéeem. Mas, às vezes, o Pum fazia muito barulho e um dia um vizinho acabou reclamando com meu pai...

Por que será que as pessoas ficam bravas quando eu solto o Pum e ele faz barulho? Por causa deste vizinho, eu tive que começar a prender o Pum toooooda noite... tooooodaaaa noooite. No começo, eu fiquei triste. Até que eu tive uma ideia geniaaaaaal: era de noite e eu estava deitado na minha cama, então soltei o Pum debaixo do meu lençol (hahahaha).

A minha mãe nunca descobriu. Teve também um dia (???) e eu fiquei segurando o pum. Mas uma hora que eu não consegui me segurar; e soltei o Pum na chuva. Minha mãe ficou brava de novo. É Porque o Pum molhado, ficou parado e com cheiro estranho (???) lá em casa. Num dia de festa, meu pai sempre pede pra gente prender o Pum.

No natal, no ano passado, quebrou (???) e eu fui parar lá na casa da tia Clotilde. E o meu pai veio e foi logo perguntando na frente de todo mundo: 'Quem foi que soltou o Pum?' 'Não fui eu, papai, não fui eu. (???)

Será que o papai acreditou? Será? Ter escapado (???) Ninguém suportava...

O pai me disse que soltar o Pum em uma festa é falta de educação e incomoda os convidados! Depois também eu criei coragem perguntei Eles sabem muito bem que a primeira vez que a tia Clotilde veio aqui em casa, ela soltou o Pum. (???)

Que a tia Clotilde solta um pum. (???) e não dá pra gente prender o tempo todo(???) eu acho todas essas broncas por causa do pum uma injustiçaaaaa! (???) mas não é culpa minha, não é de propósito, eu só não consigo segurar ele.

Agora, por exemplo, eu tô com uma vontade danada de soltar um pummmm! Será que eu posso soltar o Pum, gente? Posso, posso, posso, posso?

(26) Crianças: Não!!!

(27) Sherazade: Não posso, não? Não posso, não? Ahhh, sabe o que é que quando vem assim a vontade de soltar o Pum; eu tenho que soltar o Pum. Então agora eu vou soltar Pum, tá bom?

Um, dois, três e jááááá!

(28) Sherazade: Ahhhhh, olha o Pum aqui. O Pum é o meu melhor amigo!

(29) Sherazade: Vocês estavam pensando o quê, heim, criançada? Ahahahaha, o Pum é o nome do meu cachorrinho.

(30) Sherazade: Ahhhh, eu adoro o meu cachorrinho.

(31) Paulo: Tchau, Pum!

(32) Carlos: O cachorro chamado PUMMM! (Evento 1 - "A história contada") 
Na contação de história propriamente dita, a professora utilizou a entonação de voz para atrair atenção e interesse das crianças para a narrativa. Em relação à entonação de voz, Busatto (2013) afirma que a narrativa em uma contação de histórias não é simples e banal, pois, ao narrar, a palavra tem um papel fundamental em que o ouvir favorece a imaginação, a narrativa e o encantamento. Assim, entendemos que a estratégia de Sherazade em utilizar diferentes entonações de voz, permeadas por trocadilhos, propiciou uma melhor interação entre a professora, a história e as crianças.

Nesta microanálise, percebemos que a professora, ao escolher uma história apresentada na enunciação (25) com um tema que faz parte da contemporaneidade, conseguiu ampliar a imaginação das crianças conforme a enunciação (29) e abordar situações sobre animais de estimação. A estratégia da professora, em utilizar diversos elementos culturais que despertaram a atenção das crianças para escutar a história e desencadear o uso de recursos simbólicos (Zittoun, 2016), possibilitou compreenderem um novo sentido e significado para a palavra "pum" e, consequentemente, estabelecerem relações com seu dia a dia, como veremos na próxima microanálise.

\section{Microanálise do episódio "Discussão da história"}

Nesta microanálise, a professora estabelece a discussão sobre a história com as crianças e elas disparam a falar sobre as experiências com cachorros.

(33) Margarida: quando eu tinha cachorro a primeira vez que a gente levou ele lá na área, ele se soltou. Ele fugiu, ele se soltou mais aí a gente tava preparado às vezes tinha que por uns negócios lá pra ele não ficar latindo toda hora.

(34) Sherazade: Ah, porque latir incomoda as pessoas!

(crianças falando ao mesmo tempo)

(35) Sherazade: Deixa o Manoel falar primeiro. Incomoda as pessoas...

(36) Manoel: O cachorro dela era tão forte, mais tão forte que conseguiu fugir.

(37) Antônio: Sabia que o cachorro abriu lá atrás e cortou a coleira...

(38) Sherazade: Cortou a coleira? E o quê que aconteceu depois que ele cortou a coleira?

(39) Manoel: Ele conseguiu fugir da coleira.

(40) Sherazade: Conseguiu fugir da coleira.

(41) Isabela: tia lá no Maranhão meu tio tem dois cachorros, e bateram no Leão e ele nunca mais latiu.
(42) Sherazade: Ah tadinho, mas ele tá morando lá no mesmo lugar? A gente pode maltratar os animais?

(43) Crianças: Não, pode, não...

(44) Sherazade: Pode? Não... a gente tem que fazer carinho nos animais.

(45) Aline para a Isabela: Ele é velho?

(46) Isabela: Ele é velho.

(47) Aline: Oxi!

(48) Sherazade: deixa o Ismael falar.

(49) Sherazade: Fala Ismael...

(50) Sherazade: É, você disse que ajuda papai e mamãe. Como é que você faz? Você limpa, você ajuda a limpar o cocô? Você pega o saquinho?

(51) Ismael: É que no meu condomínio ninguém pode fazer cocô, tem que pegar um sacolinha pra por o cocô lá.

(52) Artur: Deixa eu falar.

(53) Sherazade: Isso! Olha que interessante - só um pouquinho, Artur. Olha que interessante que o Ismael falou: no condomínio ele sai com pra cachorro pra fazer cocô e não pode deixar o cocô na calçada e nem na grama tem que pegar o saquinho e pegar o cocozinho do cachorro e jogar na lixeira. É o certo.

(54) Tatiana: É vai que alguém pisa.

(55) Sherazade: Exato! Vai que alguém pisa. Alguém quer pisar em cocô de cachorro, aqui? Eu não.

(56) Artur: (...) eu pisei, porque lá tem um monte de cocô de cachorro..

\section{(57) Sherazade: Aonde, Artur?}

(58) Artur: Perto da minha casa, minha casa é aqui, perto do bloco, da, do lado, do bloco, da em frente, o bloco da da casa da professora da sala vermelha.

(59) Sherazade: Ah, tá! Olha só...

(60) Sherazade: E tem um monte de cocô, né Artur!?

(61) Artur: Até... eu vi um monte de cocô lá no restaurante.

(62) Sherazade: Ai que nojo... Que nojo, né?! Olha só, cocô tem que ser limpo! Não pode deixar o cocô... só um pouquinho, Artur! O cocô do cachorro, o cocô do cachorro 
na calçada, né?! As pessoas podem pisar, é desagradável aquele cheirinho, incomoda as pessoas; na grama, também tem que recolher o cocô. Porque muitas crianças brincam, jogam futebol na grama, não é verdade?

(63) Paulo: Éh...

(64) Manoel:... vai que eu dou um chute na bola. (Evento 4 "Aqui a gente tem um monte de historinhas...").

As experiências das crianças com cachorros foram evidenciadas no evento 4 - "Aqui a gente tem um monte de historinhas" -, quando elas disparam a narrar histórias que envolvem cachorros em seus cotidianos. Nessa vertente, Zittoun (2007, 2016) argumenta que o livro é um elemento cultural com potencialidade de alavancar recursos simbólicos quando utilizado em relação a algo que vai além de seu significado proposto e oferece formas complexas de mediação semiótica. Esses recursos exigem experiências imaginárias que podem ser utilizadas para sustentar uma experiência atual.

Assim, podemos considerar que as histórias contadas na biblioteca podem desencadear nas crianças o uso da linguagem discursiva e imaginativa, por meio da interação com histórias articuladas em suas experiências de vida. Desta forma, a colaboração para o "desenvolvimento de um argumento de discurso depende em larga medida da familiaridade com o próprio argumento. Quando as crianças falam de acontecimentos bastante conhecidos, como rotinas familiares e escolares, o desenvolvimento de um argumento é realmente facilitado" (Orsolini, 2005, p. 127).

Algumas histórias sobre cachorros, contadas pelas crianças, proporcionaram contexto para que elas pudessem expressar suas emoções por meio de narrativas. Os elementos sociais contidos na história podem disparar a utilização de recursos simbólicos e gerar a imaginação que constituirá uma ligação entre o mundo interior e a realidade compartilhada (Zittoun, 2007), pois "a narrativa da criança pressupõe a imaginação, uma vez que ao narrar ela dispõe dos elementos de sua experiência, criando algo novo ou novos sentidos para aquilo que já é” (Cruz, 2011, p. 100).

\section{Microanálise do episódio "Charlote realidade na biblioteca"}

O episódio registrado apresenta a história da Charlote, contada com apoio da exibição de foto que mostra a professora e seu animal de estimação.

(65) Sherazade: Olha só, deixa eu só falar pra vocês... A tia Sherazade também tem uma cachorrinha, olha aqui.

(66) Artur: quem é?

(67) Sherazade: Ela já não está mais desse tamanho! Ela já está bem grandinha...
(68) Artur: quem é essa?

(69) Sherazade: Essa aqui é a tia Sherazade e essa é a cachorrinha dela; vou passar mostrando pra vocês. O nome dela é Charlote!

(70) Sherazade: Charlote é uma cachorrinha pretinha... posso falar? Contar a história? Posso? A Charlote é uma cachorrinha pretinha, e ela foi adotada pela minha família. Sabe como é que nós encontramos essa cachorrinha?

\section{(71) Júlio: na rua}

(72) Sherazade: Abandonada na rua. Ela estava magrinha, com fome, suja, cheia de pulgas, certamente ela estava doentinha... O meu filho com a namorada dele. Eles estavam andando na rua, e ela seguia, seguia, seguia. Onde o meu filho e a namorada iam, ai ela também ia atrás. A namorada do meu filho quis pegar a cachorrinha pra cuidar. Levou pra casa onde nós estávamos e deu comidinha, colocou um lençolzinho pra ela ficar em cima, deu um banho... e então ela ficou com pena de deixar aquele cachorrinho de novo na rua; era a cachorrinha, na verdade, ela é, porque ela ainda está viva. Então quê que nós fizemos? Trouxemos ela pra Brasília. aí aqui levamos ela primeiro ao médico dos animais.

(73) Sherazade: Quem sabe o nome do médico dos animais?

(74) Sherazade: Veterinário...

(75) Sherazade: Onde, quando eu peguei? É uma cidade do interior, lá as pessoas têm o hábito de largar, os cachorrinhos na rua, abandonar mesmo. Às vezes elas não querem e largam os cachorrinhos na rua. E essa cachorrinha foi encontrada abandonada. Então trouxemos ela pra cá levamos ao médico o médico cuidou dela passou um remedinho pra pulga é deu vacina nela deu banho cuidou direitinho. Ela ficou morando com a gente, ela era desse tamanhinho. Agora, ela já está desse tamanho sabe quantos anos ela tem? Com quantos anos ela está agora?

(76) Artur: 20

(77) Sherazade: Cinco aninhos...

(crianças falando ao mesmo tempo)

(78) Sherazade: Então, essa cachorrinha, quando chega visita em casa, ela fica numa felicidade, mais numa felicidade tão grande que ela quer pular em quem chega lá em casa: balança o rabinho e enquanto ela não pula, pula, pula, e lambe a pessoa, ela não sossega. E quando chega uma pessoa lá em casa, eu abro a porta assim, e falo assim: 'Prepara, que agora é hora da Charlotte pular em você'. E a pessoa já fica preparada, né?! Porque sabe que a Charlotte vai pular em cima dela. Mas é um pulo de alegria, né?! Porque ela tá vendo uma pessoa diferente dentro de casa, 
né?! Tá bom? E assim, acabou a nossa história de hoje; eu quero saber se vocês gostaram da nossa história? Gostaram da nossa conversa hoje?

\section{(79) Crianças: Simmmm!!!}

(80) Sherazade: Foi legal, né!?! (Evento 1 - "Prepara, que agora é a hora da Charlote").

Na microanálise "Charlote realidade na biblioteca", a professora possibilitou a ampliação de sentido das crianças, por meio de uma fotografia em que estavam retratadas ela e Charlote, sua cachorra de estimação. Neste evento "Prepara, que agora é a hora da Charlote" -, Sherazade, no enunciado (69), com uma voz cadenciada, tentou envolver as crianças com a fotografia; e elas, atentas, olhavam com interesse e curiosidade para a foto. Neste sentido, Luria (2006) afirma que o ser humano, em seu desenvolvimento, não está reduzido a simples reflexos tipo estímulo-resposta: ele consegue estabelecer conexões indiretas entre a estimulação que recebe e as respostas que emite por meio de vários elos de mediação contidos no contexto sociocultural.

Sherazade narrou para as crianças, nos enunciados (72), (73), (74) e (75), os detalhes sobre a chegada da Charlote em sua vida, enfatizando a responsabilidade social, de cidadania e de respeito aos animais. A professora utilizou a história da Charlote como recurso simbólico que pode ser usado para algo além de seu objetivo imediato, em uso secundário como mediação para que possa fazer sentido para outras pessoas em situações específicas (Zittoun, 2016).

A estratégia utilizada por Sherazade para atrair atenção das crianças não imprimiu somente questões estéticas, mas também parte de uma experiência de cunho social. Desta forma, Pinto e Branco (2009) entendem que a função da mediação cultural é importante e, nesse sentido, ela é exercida pelo grupo social no qual as crianças se inserem, e é um meio extremamente rico para que as produções simbólicas sejam constituídas.

Ao proporcionar momentos reflexivos a respeito do abandono de animais e os cuidados necessários, Sherazade utilizou a memória afetiva e imaginativa para expandir sua interação com as crianças. Sendo a imaginação uma atividade extraordinariamente rica em momentos emocionais, parte-se da ideia de que seu motor principal seja o afeto (Vigotsky, 2004/2009).

Sherazade encerrou a sessão de contação de histórias, apresentado no enunciado (78), cantando a paródia para as crianças sobre como ela recebia suas visitas avisando sobre as ações da Charlote, e as crianças se mostraram animadas e interessadas, de acordo com a enunciação (79), esboçando sorrisos. Assim, para Mozzer e Borges (2008), a contação de histórias deve ser vista como recurso lúdico e importante para o desenvolvimento das crianças, por abranger situações que envolvem pensamento, imaginação, fantasia e criação, propiciando a construção de sentidos e significados em suas vivências.
No que diz respeito às interações ocorridas no contexto de contação de histórias, percebemos o quanto a imaginação e o uso de recursos simbólicos proporcionaram diálogos, interações e expansão da imaginação (Zittoun \& Cerchia, 2013) em todos os envolvidos no contexto analisado. Sendo assim, não há um antagonismo entre realidade e imaginação, uma vez que são subtraídos da realidade os elementos culturais para a composição dos diálogos e o desencadeamento dos recursos simbólicos. Isso implica que o processo de contação de histórias, permeado pelas narrativas cotidianas tanto da professora quanto das crianças, propicia o desenvolvimento no humano.

\section{Considerações finais}

O presente estudo ocupou-se em analisar a interação entre uma professora e crianças e a importância da contação de histórias como uma atividade que desencadeia os recursos simbólicos - e, consequentemente, a expansão da imaginação (Zittoun, 2016). Nesta pesquisa, embasamo-nos no aporte teórico da Psicologia Histórico-Cultural por entendermos que os processos interativos mediados por dispositivos semióticos promovem o desenvolvimento humano.

As interações estabelecidas no contexto da biblioteca favoreceram o desenvolvimento dos participantes, pois este espaço está permeado por múltiplas linguagens, sejam elas verbais ou não verbais. O fato de ser uma pesquisa qualitativa possibilitou a aproximação da ocorrência dos processos interativos e, nesta perspectiva, consideramos que a videogravação como recurso para análise de dados foi preponderante para realização da pesquisa.

Este contexto de biblioteca analisado oferece condição favorável para a promoção do desenvolvimento infantil a partir das interações entre a professora e as crianças, criança-criança e criança-ambiente por propiciar narrativas ficcionais e cotidianas. A contação de histórias ocorrida de forma interativa potencializou o uso de recursos simbólicos quando os participantes fizeram referências às suas experiências cotidianas permeadas por afetividade, o que, consequentemente, desencadeou a expansão dos processos imaginativos.

Este estudo analisou as interações ocorridas em um contexto específico de biblioteca escolar a partir da dinamicidade da atividade de contação de histórias. Por conta disso, não é possível generalizar os resultados obtidos para outros espaços de biblioteca.

Ao longo do desenvolvimento desta pesquisa, identificamos que investigações futuras poderão se ater aos processos interacionais atrelados aos arranjos semióticos e às negociações de significados para a tomada de sentidos (Valsiner, 2012; Zittoun, 2007, 2016) dos participantes, dada a importância educacional da atividade de contação de histórias e seus impactos no processo de desenvolvimento. 


\section{Referências}

Bakhtin, M. (2014). Marxismo e filosofia da linguagem (Lahud, M.; Vieira, Y.F., Trads.) São Paulo: Hucitec. (Trabalho original publicado em 1929)

Bauer, M.W.; Gaskell, G. (2002). Pesquisa qualitativa com texto, imagem e som: um manual prático. (Guareschi, P.A., Trad.). Petrópolis: Vozes.

Bruner, J.S. (2002). Atos de significação. Porto Alegre: Artmed.

Busatto, C. (2013). A arte de contar histórias no século XXI: Tradição e ciberespaço. Petrópolis: Vozes.

Caixeta, J.E. (2006). Guardiãs da memória: Tecendo significações de si, suas fotografias e seus objetos. (Tese de Doutorado). Instituto de Psicologia, Universidade de Brasília, Brasília.

Carvalho, A.M. (1996). O uso do vídeo na tomada de dados: pesquisando. O desenvolvimento do ensino em sala de aula. ProPosições, 19 (1), 5-13.

Creswell, J.W. (2014). Investigação qualitativa e projeto de pesquisa: escolhendo entre cinco abordagens (Rosa, S.M., Trad.). Porto Alegre: Penso.

Cruz, M.N. (2011). Imaginação, linguagem e elaboração de conhecimento na perspectiva da psicologia histórico-cultural. In: Nogueira, A.L.H.; Bustamante, A.L. (Orgs.), Emoção, memória, imaginação: a constituição do desenvolvimento humano na história e na cultura (pp. 85- 103). Campinas: Mercado das Letras.

Daniels, H. (2008). Vygotsky e a pesquisa (Bini, E. Trad.). São Paulo: Edições Loyola.

Luria, A.R. (2006). O cérebro humano e a atividade consciente. In: Vigotskyi, L.S.; Luria, A.R.; Leontiev, A.N. (Orgs.), Linguagem, desenvolvimento e aprendizagem (pp. 191-224). São Paulo: Ícone.

Moreno, L.A. (2009). O lúdico e a contação de histórias na Educação Infantil. Cadernos de Pesquisa Interdisciplinar em Ciências Humanas, 10 (97), 228-241.

Mozzer, G.N.S.; Borges, F.T. (2008). A criatividade infantil na perspectiva de Lev Vigotsky. Inter-ação, (33), 69-88.
Orsolini, M. (2005). A construção do discurso nas discussões em sala de aula: Uma análise sequencial. In: Pontecorvo, C.; Ajello, A.M.; Zucchermaglio, C. (Orgs.), Discutindo se aprende: Interação social, conhecimento e escola (pp.123-144). Porto Alegre: Artmed.

Pino, A. (2005). As marcas do humano: Às origens da constituição cultural da criança na perspectiva de Lev S. Vigotsky. São Paulo: Cortez.

Pino, A. (2006). A produção imaginária e a formação do sentido estético. Reflexões úteis para uma educação humana. ProPosições, 1(1), 47-70.

Pinto, R.G.; Branco, A,U. (2009). Práticas de socialização e desenvolvimento na educação infantil: contribuições da psicologia sociocultural. Temas em Psicologia, 17(2), 511-525.

Pontecorvo, C.; Ajello, A.M.; Zucchermaglio, C. (2005). Discutindo se aprende: Interação social, conhecimento e escola (C. Bressan \& S. Termognoni, Trads.). Porto Alegre: Artmed.

Silva, D.N.H. (2012). Imaginação, criança e escola. São Paulo: Summus.

Valsiner, J. (2012). Fundamentos da psicologia cultural (Bastos, A.C.S., Trad.). Porto Alegre: Artmed.

Vigotsky, L.S. (2007). A formação social da mente (Neto., J. C.; Barreto, L.S.M.; Afeche, S.C., Trads.). São Paulo: Martins Fontes. (Trabalho original publicado em 1984)

Vigotsky, L.S. (2009). Imaginação e criação na infância (Prestes, Z.R., Trad.) São Paulo: Ática. (Trabalho original publicado em 2004)

Vigotski, L.S. (2010). Psicologia pedagógica. São Paulo: Martins Fontes. (Trabalho original publicado em 2001).

Zittoun, T. (2007). The Role of Symbolic Resources in Human Lives. In: Valsiner, J.; Rosa, A. (Orgs.), The Cambridge Handbook of SocioCultural Psychology. Cambridge: Cambridge University Press.

Zittoun, T. (2016). Symbolic resources and sense-making in learning and instruction. European Journal of Psychology of Education, $1-20$.

Zittoun, T.; Cerchia, F. (2013). Imagination as expansion of experience. Integrative Psychological and Behavioral Science, 47, 305-324. 


\section{Sobre as autoras}

Silvana Goulart Peres (sgperes@gmail.com)

Pedagoga e Mestra em Processos de Desenvolvimento Humano e Saúde. Universidade de Brasília-Brasília- DF. https://orcid.org/0000-0002$9465-5440$

Renata Magalhães Naves (renatanavespsico@gmail.com)

Psicóloga e Doutoranda em Processos de Desenvolvimento Humano e Saúde. Universidade de Brasília-Brasília- DF. https://orcid.org/0000-00027423-1309

Fabrícia Teixeira Borges (fabricia.borges@gmail.com)

Professora Doutora do Programa de Pós-Graduação em Desenvolvimento Humano e Saúde - UnB. Universidade de Brasília-Brasília- DF. https:// orcid.orq/0000000293412738 unrestricted use, distribution and reproduction in any medium, provided the original article is properly cited. 
